\title{
Seletividade de herbicidas aplicados em pós-emergência em pinhão manso (Jatropha curcas L.) ${ }^{1}$
}

\author{
Selectivity of herbicides applied in post-emergence on physic nut \\ (Jatropha curcas L.)
}

\section{Karoline Santos Gonçalves ${ }^{2}$, Alcebíades Rebouças São José ${ }^{3}$, Sidnei Douglas Cavalieri ${ }^{4}$, Ione Sousa Braga Martins ${ }^{5}$, Edvaldo Domingues Velini ${ }^{6}$}

\begin{abstract}
Resumo - A inexistência de herbicidas seletivos registrados para o pinhão manso torna difícil o controle químico de plantas daninhas, principalmente nos estádios iniciais de desenvolvimento. Objetivou-se com este trabalho, avaliar a seletividade de herbicidas aplicados em pós-emergência em pinhão manso (Jatropha curcas L.). O experimento foi conduzido em delineamento inteiramente casualizado, em arranjo fatorial $(3 \times 5)+1 \mathrm{com} 11$ repetições, sendo o primeiro fator constituído por herbicidas e o segundo por dosagens de cada um deles, mais uma testemunha adcional sem aplicação. Os herbicidas e as suas respectivas dosagens foram: glyphosate (180, 450, 720, 990 e $\left.1.260 \mathrm{~g} \mathrm{ha}^{-1}\right)$, fluazifop-p-butil (100, 125, 150, 175 e $\left.200 \mathrm{~g} \mathrm{ha}^{-1}\right)$ e 2,4-D (720, $1.080,1.440,1.800$ e $2.160 \mathrm{~g} \mathrm{ha}^{-1}$ ). Os herbicidas foram aplicados 55 dias após a semeadura, quando as plantas apresentavam dois a três pares de folhas verdadeiras. Apenas o glyphosate (180 $\left.\mathrm{g} \mathrm{ha}^{-1}\right)$ e o fluazifop-p-butil (125 $\left.\mathrm{g} \mathrm{ha}^{-1}\right)$ apresentaram-se seletivos ao pinhão manso, mostrandose promissores para o controle de plantas daninhas em lavouras jovens. Nenhum dos herbicidas afetou a altura das plantas, no entanto, os herbicidas glyphosate (nas demais dosagens) e 2,4-D, demonstraram efeitos tóxicos com alterações no aspecto e morfologia das plantas.
\end{abstract}

Palavras-chave: Jatropha curcas L.; fitotoxicidade; controle químico.

Abstract - The lack of information on herbicides selective for cultivation of physic nut makes it difficult to tame the chemical control of weeds, especially during the initial stage of the crop. Therefore, the objective of this study was to evaluate the selectivity of herbicides applied in postemergence to the culture of physic nut (Jatropha curcas L.). We used experimental design completely randomized with 16 treatments and 11 repetitions, three herbicides in five doses and a control without herbicide. The doses of herbicides $\left(\mathrm{L} \mathrm{ha}^{-1}\right)$ were: glyphosate $(180,450,720,990$ and $\left.1.260 \mathrm{~g} \mathrm{ha}^{-1}\right)$, fluazifop-p-butyl $\left(100,125,150,175\right.$ e $\left.200 \mathrm{~g} \mathrm{ha}^{-1}\right)$ and 2,4-D amine (720,

\footnotetext{
${ }^{1}$ Recebido para publicação em 18/04/2011 e aceito em 10/08/2011

2 Eng. ${ }^{\circ}$ Agr. ${ }^{\circ}$, M.Sc., Doutoranda em Irrigação e Drenagem. Departamento de Engenharia Rural, Faculdade de Ciências Agronômicas - FCA/UNESP. Rua José Barbosa de Barros, 1780, 18603-970 Botucatu-SP. karolinesg@fca.unesp.br

${ }^{3}$ Eng. ${ }^{\circ}$ Agr. ${ }^{\circ}$, D.Sc., Professor Adjunto. Departamento de Fitotecnia e Zootecnia, Universidade Estadual do Sudoeste da Bahia - UESB. Estrada do Bem Querer Km 4, 45083-900 Vitória da Conquista-BA. alreboucas@ gmail.com

${ }^{4}$ Eng. $^{\circ}$ Agr. ${ }^{\circ}$, D.Sc., Pesquisador da Embrapa Hortaliças. Rod. BR 060 km 9 Brasília/Anápolis, 70359-970 BrasíliaDF. cavalieri@cnph.embrapa.br

${ }^{5}$ Eng. ${ }^{\text {O Agr. }}$, M.Sc., Mestranda em Fitotecnia. Departamento de Fitotecnia e Zootecnia, Universidade Estadual do Sudoeste da Bahia - UESB. Estrada do Bem Querer Km 4, 45083-900 Vitória da Conquista-BA. ioneagron@gmail.com

${ }^{6}$ Professor Livre-Docente. Departamento de Produção Vegetal, Faculdade de Ciências Agronômicas - FCA/UNESP. Rua José Barbosa de Barros, 1780, 18603-970 Botucatu-SP. velini@ fca.unesp.br.
} 
$1.080,1.440,1.800$ e $2.160 \mathrm{~g} \mathrm{ha}^{-1}$ ). The herbicides were applied 55 days after sowing, when the plant seedlings had two to three pairs of leaves. Of the three herbicides applied in postemergency, only fluazifop-p-butyl and glyphosate at the lower dose, was completely selective to plant seedlings physic nut and is promising for the control of weeds in young plantations. None of the herbicides affected the height of the plant seedlings, though the herbicide glyphosate (in higher doses) and 2,4-D amine showed toxic effects with changes in appearance and morphology of plant seedlings.

Keywords: Jatropha curcas L.; phytotoxicity; chemical control.

\section{Introdução}

O pinhão manso (Jatropha curcas L.) é uma planta medicinalmente potente, com grande capacidade de produção de óleo, sendo que, entre as oleaginosas, é um dos favoritos para a produção de biodiesel (Nunes et al., 2006). Adicionalmente à capacidade de produzir óleo vegetal, essa planta é tolerante a deficiência hídrica, sendo menos exigente em nutrientes, além de apresentar capacidade de recuperação de áreas degradadas em função da formação de raízes profundas, crescendo até em solos de baixa fertilidade (Teixeira, 2005).

Diante de sua reconhecida importância no cenário dos combustíveis alternativos, problemas como o controle de plantas daninhas em lavouras jovens, vêm sendo relatado como empecilho para a recente introdução do pinhão manso no setor agrícola em decorrência da carência de informações sobre técnicas de manejo adequado. Segundo Saturnino et al. (2005) esta espécie é susceptível à competição com as plantas daninhas nos estádios iniciais de desenvolvimento, sendo necessário o controle mecânico e/ou químico durante as fases de estabelecimento da cultura.

O glyphosate é um herbicida de amplo espectro, não-seletivo, muito utilizado na agricultura para o controle de gramíneas e folhas largas anuais e perenes. Este herbicida atua inibindo enzimas específicas, suspendendo a síntese de aminoácidos aromáticos (Araújo, 2002). Segundo Vargas \& Roman (2003), após a aplicação do glyphosate, os sintomas de fitotoxicidade nas plantas caracterizam-se pelo amarelecimento dos meristemas, progredindo para necrose e morte das plantas.

O 2,4-D possui ação hormonal, com inibição da síntese de RNA e proteínas (Rocha, 2003). Após a aplicação desse herbicida em plantas sensíveis, verifica-se rapidamente aumentos significativos da enzima celulase, notadamente nas raízes. O 2,4-D apresenta seletividade para plantas de folhas estreitas, tendo maior fitotoxicidade quando aplicado em plantas de folhas largas (dicotiledôneas). Sua toxidez se manifesta por meio de vários efeitos, como: epinastia das folhas, retorcimento do caule, engrossamento das gemas terminais, surgimento de raízes secundárias e destruição do sistema radicular, o que consequentemente, resulta na morte das plantas em poucos dias (Ferreira et al., 2005; Severino et al., 2004).

O fluazifop-p-butil é um herbicida seletivo de ação sistêmica, que transloca-se apossimplasticamente, concentrando-se nos pontos de crescimento das plantas, provocando sua morte. É um herbicida específico para o controle de gramíneas anuais e perenes nas culturas do algodão, alface, cebola, cenoura, batata, feijão, soja e tomate. Alguns autores observaram efeitos tóxicos quando este herbicida foi utilizado nas culturas de mandioquinha-salsa (Freitas et al., 2004), melão e pepino (Vidal et al., 2000). 
Comparado ao controle mecânico, o controle químico de plantas daninhas apresenta vantagens, devido à economia de custos com mão-de-obra, além de apresentar maior agilidade na obtenção de resultados, principalmente em áreas extensas. Contudo, para se realizar o controle químico, são necessários estudos acerca da seletividade de herbicidas a serem aplicados na cultura.

Desta forma, objetivou-se com este trabalho, avaliar a seletividade dos herbicidas glyphosate, fluazifop-p-butil e 2,4-D, aplicados em pós-emergência, na cultura do pinhão manso.

\section{Material e métodos}

O experimento foi conduzido na Área Experimental do campus da Universidade Estadual do Sudoeste da Bahia, em Vitória da Conquista, no período de março a julho de 2008. O município está localizado na microrregião do planalto da Conquista, Sudoeste do estado da Bahia, numa altitude superior a 900 metros, com as seguintes coordenadas geográficas: $14^{\circ} 50$ '53" de latitude Sul e 4050'19" de longitude Oeste. As médias das temperaturas máxima e mínima do ar são, respectivamente, de $25,3^{\circ} \mathrm{C}$ e de $16,1^{\circ} \mathrm{C}$. A precipitação média anual é de $733,9 \mathrm{~mm}$, concentradas em sua maioria entre os meses de novembro a março.

Para a realização do experimento, foram utilizadas mudas provenientes de sementes de pinhão manso com um ano de colhidas. Para obtenção das mudas, as sementes foram colocadas em sacos plásticos com dimensões de $20 \times 36 \mathrm{~cm}$, contendo quatro litros de substrato composto de uma mistura de solo e esterco de curral curtido na proporção de 3:1, 2 $\mathrm{kg} \mathrm{m} \mathrm{m}^{-3}$ de $\mathrm{P}_{2} \mathrm{O}_{5}$, na forma de superfosfato simples, $1 \mathrm{~kg} \mathrm{~m}^{-3} \mathrm{~K}_{2} \mathrm{O}$, na forma de cloreto de potássio e $2 \mathrm{~kg} \mathrm{~m}^{-3}$ de calcário dolomítico, para a germinação e emergência das plântulas. Os sacos foram mantidos em viveiro com $50 \%$ de sombreamento e irrigados conforme necessidade. Após 40 dias da emergência, as plantas, foram transferidas para a área externa permanecendo a pleno sol por 15 dias antes da aplicação dos tratamentos. Os herbicidas foram aplicados com um pulverizador costal de precisão, pressurizado com $\mathrm{CO}_{2}$, operando à

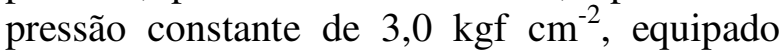
com barra com bicos contendo duas pontas de pulverização tipo leque 110.02 , a uma altura de $50 \mathrm{~cm}$ das plantas, com vazão equivalente a $200 \mathrm{~L} \mathrm{ha}^{-1}$ de calda. As caldas de pulverização foram adicionadas com $0,3 \quad \mathrm{~mL} \mathrm{~L}^{-1}$ do espalhante adesivo do grupo químico alquil fenóis etoxilado $\left(\right.$ Agral $\left.^{\circledR}\right)$. No momento da aplicação observou-se $19,8^{\circ} \mathrm{C}$ de temperatura, $78 \%$ de umidade relativa, $20 \%$ de nebulosidade e ventos não superiores a $4,3 \mathrm{~km} \mathrm{~h}^{-1}$.

As unidades experimentais consistiam em uma muda de pinhão manso, acondicionadas em sacos plásticos no qual foram aplicados os tratamentos 55 dias após a semeadura, quando as plantas apresentavam dois a três pares de folhas verdadeiras.

$\mathrm{O}$ experimento foi conduzido em delineamento inteiramente casualizado, em arranjo fatorial $(3 \times 5)+1$ com 11 repetições, totalizando 176 unidades experimentais, sendo o primeiro fator constituído pelos herbicidas (glyphosate, fluazifop-p-butil e 2,4-D) e o segundo por cinco doses de cada um deles: glyphosate $\left(180,450,720,990\right.$ e $\left.1.260 \mathrm{~g} \mathrm{ha}^{-1}\right)$, fluazifop-p-butil $(100,125,150,175$ e $200 \mathrm{~g}$ $\left.\mathrm{ha}^{-1}\right)$ e $2,4-D(720,1.080,1.440,1.800$ e 2.160 $\mathrm{g} \mathrm{ha}^{-1}$ ), mais uma testemunha adicional, sem aplicação.

Durante a condução do experimento, os sintomas visuais de fitotoxicidade foram avaliados em relação à testemunha aos 9,18 , 27 e 36 dias após a aplicação (DAA) para plantas tratadas com glyphosate e aos 7, 14, 21 e 28 DAA para plantas tratadas com fluazifopp-butil, atribuindo-se valores de 0 a $100 \%$ em 
função da intensidade dos sintomas, em que zero correspondia à ausência de sintomas e $100 \%$ a morte das plantas (SBCPD, 1995).

Aos 50 dias após a aplicação dos tratamentos, avaliaram-se a altura das plantas, medindo-se a região compreendida entre o colo e a gema apical, o diâmetro do caule, o número de folhas e a massa seca da parte aérea e do sistema radicular. Após o corte da parte aérea, o sistema radicular foi lavado em água corrente para retirada total do solo e determinado seu comprimento. Em seguida, a parte aérea e as raízes foram pesadas e acondicionadas separadamente em sacos de papel Kraft e levadas para secar em estufa de circulação forçada de ar a $70^{\circ} \mathrm{C}$ por 4 dias, até atingirem massa constante, para determinação da massa seca.

Todas as variáveis obtidas foram submetidas à análise de variância pelo teste $\mathrm{F}$ e, para comparação da média da testemunha com os demais tratamentos foi aplicado o teste Dunnett a 5\% de probabilidade.

\section{Resultados e discussão}

Houve diferenças significativas $(p<0,01)$ entre os herbicidas aplicados sobre as plantas de pinhão manso para as variáveis avaliadas. Para os herbicidas glyphosate e fluazifop-p-butil houve efeito significativo do modelo quadrático para todas as características, com exceção do comprimento da raiz, que foi significativo no modelo linear para o glyphosate e não houve significância em nenhum dos modelos para o fluazifop-p-butil. Para o herbicida 2,4-D, não se observou significância para todas as características avaliadas (Quadro 3).

Quadro 3 - Resumo da análise de variância da altura, diâmetro, número de folhas (NF), comprimento de raiz (CR) e matéria fresca (MFPA) e seca (MSPA) da parte aérea e matéria fresca (MFR) e seca (MSR) da raiz de plantas de pinhão manso aos 50 DAA.

\begin{tabular}{|c|c|c|c|c|c|c|c|c|c|}
\hline \multirow{2}{*}{$\begin{array}{l}\text { Fonte de } \\
\text { variação }\end{array}$} & \multirow{2}{*}{ G.L. } & \multicolumn{8}{|c|}{ Quadrados Médios } \\
\hline & & Altura & Diâmetro & $\mathbf{N F}$ & $\mathbf{C R}$ & MFPA & MSPA & MFR & MSR \\
\hline Tratamentos & 15 & $69,65^{* *}$ & $2,50^{* *}$ & $307,28^{* * *}$ & $1126,95^{* * *}$ & $5087,68^{* * *}$ & $295,54^{* * *}$ & $586,35^{* *}$ & $29,15^{* * *}$ \\
\hline gly & 4 & $52,86^{* *}$ & $1,45^{* *}$ & $250,70^{* * *}$ & $552,91^{* * *}$ & $3361,20^{* * *}$ & $257,27^{* * *}$ & $466,01^{* * *}$ & $17,19^{* *}$ \\
\hline Linear & 1 & $57,60^{* * *}$ & $3,49^{* * *}$ & $619,28^{* * *}$ & $1330,06^{* * *}$ & $6521,59^{* * *}$ & $688,25^{* * *}$ & $917,40^{* * *}$ & $37,82^{* * *}$ \\
\hline Quadrático & 1 & $104,07^{* * *}$ & $1,31^{* * *}$ & $294,60^{* * *}$ & 166,44 & $2899,12^{* * *}$ & $217,91^{* * *}$ & $400,83^{* * *}$ & $13,02^{* * *}$ \\
\hline flu & 4 & $40,49^{\text {*** }}$ & $0,40^{* * *}$ & $16,03^{* * *}$ & $118,91^{*}$ & $2922,50^{* * *}$ & $113,48^{* * *}$ & 79,35 & $14,83^{\text {*** }}$ \\
\hline Linear & 1 & 9,780 & 0,01 & 7,13 & 138,21 & 428,12 & 2,00 & 0,64 & 1,75 \\
\hline Quadrático & 1 & $119,05^{* *}$ & $1,42^{* * *}$ & $54,96^{* * *}$ & 11,18 & $7175,6^{* * *}$ & $904,16^{* * *}$ & $279,67^{* * *}$ & $50,41^{* * *}$ \\
\hline 2,4-D & 4 & 5,08 & 0,11 & 1,70 & 33,68 & 40,17 & 2,94 & 42,65 & 1,27 \\
\hline Linear & 1 & 4,97 & 0,04 & 11,88 & 94,86 & 30,80 & 3,73 & 13,00 & 0,48 \\
\hline Quadrático & 1 & 0,07 & 0,01 & 1,74 & 5,63 & 39,32 & 1,05 & 3,73 & 0,47 \\
\hline ERRO & $142(129)$ & 7,73 & 0,086 & 4,11 & 47,32 & 290,22 & 16,11 & 39,61 & 1,33 \\
\hline $\mathrm{CV}(\%)$ & & 16,97 & 13,378 & 26,86 & 17,88 & 31,47 & 34,85 & 32,83 & 31,60 \\
\hline Média Geral & & 16,38 & 2,19 & 7,55 & 38,48 & 54,13 & 11,52 & 19,17 & 3,66 \\
\hline
\end{tabular}

gly - glyphosate; flu - fluazifop-p-butil; 2,4-D - 2,4-D amina

O herbicida fluazifop-p-butil, nas cinco doses aplicadas, apresentou-se como de maior seletividade às plantas de pinhão manso, pois não afetou nenhuma das variáveis avaliadas.
As médias das variáveis foram superiores ou não diferiram das médias da testemunha (Quadro 4). Resultados semelhantes foram obtidos por Ronchi \& Silva (2003) e Alcântra 
(2000), ao testar a tolerância de plantas de café ao fluazifop-p-butil.

Nenhum dos três herbicidas causou alterações na altura das plantas em relação à testemunha. O herbicida 2,4-D causou redução para todas as outras variáveis avaliadas, com exceção da dose $1.440 \mathrm{~g} \mathrm{ha}^{-1}$ que não diferiu da testemunha quanto à média da massa fresca e seca da raiz (Quadro 4). Severino et al. (2004), ao testar doses de 40,80,120 e 160 ppm de 2,4-D, observaram resultados semelhantes em plantas de mamoneira que apresentaram reduções na altura e no número de folhas a partir da menor dose aplicada (40 ppm) . Do mesmo modo, Albuquerque et al. (2008a) observaram que o 2,4-D provocou diminuição na altura das plantas de pinhão manso. $\mathrm{O}$ herbicida glyphosate, quando aplicado na menor dose (180 $\left.\mathrm{g} \mathrm{ha}^{-1}\right)$, provocou diferença das plantas em relação à testemunha para o diâmetro do caule, número de folhas e massa seca da parte aérea, que apresentaram médias superiores à testemunha. Já para a maior dose $\left(1.260 \mathrm{~g} \mathrm{ha}^{-1}\right)$, as médias das variáveis foram inferiores às observadas na testemunha, com exceção da altura, que não diferiu da testemunha (Quadro 4).

Quadro 4 - Diferenças entre as médias dos tratamentos e da testemunha para altura, diâmetro, número de folhas (NF), comprimento de raiz (CR) e matéria fresca (MFPA) e seca (MSPA) da parte aérea e matéria fresca (MFR) e seca (MSR) da raiz de plantas de pinhão manso aos 50 dias após a aplicação dos herbicidas.

\begin{tabular}{lcccccccc}
\hline Comparações & Altura & Diâmetro & NF & CR & MFPA & MSPA & MFR & MSR \\
\hline gly 180 vs. Testemunha & 2,136 & $0,436^{*}$ & $3,364^{*}$ & 1,72 & 17,93 & $6,32^{*}$ & 5,70 & 0,74 \\
\hline gly 450 vs. Testemunha & $-3,227$ & $-0,318$ & $-6,273^{*}$ & $-5,82$ & $-24,23^{*}$ & $-3,50$ & $-9,77^{*}$ & $-2,12^{*}$ \\
\hline gly 720 vs. Testemunha & $-3,091$ & $-0,182$ & $-7,182^{*}$ & $-3,94$ & $-13,52$ & $-3,27$ & $-5,23$ & $-1,35$ \\
\hline gly 990 vs. Testemunha & $-2,009$ & $-0,482^{*}$ & $-7,636^{*}$ & $-17,28^{*}$ & $-19,49$ & $-4,93$ & $-9,09^{*}$ & $-2,15^{*}$ \\
\hline gly 1.260 vs. Testemunha & $-2,091$ & $-0,373^{*}$ & $-7,818^{*}$ & $-9,94^{*}$ & $-22,94^{*}$ & $-5,47^{*}$ & $-9,07^{*}$ & $-2,18^{*}$ \\
\hline flu 100 vs. Testemunha & $5,227^{*}$ & $0,582^{*}$ & $3,818^{*}$ & 1,30 & $25,72^{*}$ & $5,88^{*}$ & 6,92 & $1,97^{*}$ \\
\hline flu 125 vs. Testemunha & 0,345 & 0,155 & 1,909 & 7,31 & $-13,60$ & $-1,66$ & 4,11 & $-0,48$ \\
\hline flu 150 vs. Testemunha & 1,227 & 0,146 & 0,636 & 3,53 & 6,79 & 0,23 & 2,27 & 0,13 \\
\hline flu 175 vs. Testemunha & 1,582 & 0,300 & 1,546 & 2,79 & 6,74 & 1,33 & 1,75 & 0,43 \\
\hline flu 200 vs. Testemunha & 3,1180 & $0,4636^{*}$ & $2,7273^{*}$ & $9,16^{*}$ & $25,42^{*}$ & $5,06^{*}$ & 7,71 & $2,142^{*}$ \\
\hline 2,4-D 720 vs. Testemunha & $-3,1610$ & $-0,8114^{*}$ & $-9,2841^{*}$ & $-21,48^{*}$ & $-42,46^{*}$ & $-10,54^{*}$ & $-13,21^{*}$ & $-2,891^{*}$ \\
\hline 2,4-D 1.080 vs. Testemunha & $-1,6360$ & $-0,8530^{*}$ & $-9,9091^{*}$ & $-23,08^{*}$ & $-41,03^{*}$ & $-10,65^{*}$ & $-13,133^{*}$ & $-3,176^{*}$ \\
\hline 2,4-D 1.440 vs. Testemunha & $-1,8030$ & $-0,6364^{*}$ & $-9,5758^{*}$ & $-18,48^{*}$ & $-42,35^{*}$ & $-9,55^{*}$ & $-6,99$ & $-1,976$ \\
\hline 2,4-D 1.800 vs. Testemunha & $-3,4740$ & $-0,9864^{*}$ & $-10,409^{*}$ & $-25,16^{*}$ & $-47,83^{*}$ & $-11,90^{*}$ & $-17,06^{*}$ & $-3,669^{*}$ \\
\hline 2,4-D 2.160 vs. Testemunha & $-2,0470$ & $-0,7919^{*}$ & $-10,242^{*}$ & $-26,33^{*}$ & $-43,17^{*}$ & $-11,12^{*}$ & $-13,95^{*}$ & $-3,055^{*}$ \\
\hline
\end{tabular}

gly - glyphosate; flu - fluazifop-p-butil; 2,4-D - 2,4-D amina *Significativo ao nível de 5\% de probabilidade pelo teste de Dunnett.

Todas as características avaliadas para o glyphosate apresentaram redução à medida que as doses do herbicida foram elevadas até a dose $990 \mathrm{~g} \mathrm{ha}^{-1} \mathrm{e}$, a partir daí aumentaram com a elevação das doses (Figuras 1 a 7 ), com exceção do comprimento da raiz, que apresentou redução proporcional ao aumento das doses do herbicida (Figura 8). Para o herbicida fluazifop-p-butil, as variáveis altura, diâmetro, número de folhas e massa fresca da raiz apresentaram redução até a dose $150 \mathrm{~g}$ ha ${ }^{1}$ e a partir dessa dose tiveram aumento. Para as outras variáveis, massa fresca e seca da parte aérea e massa seca da raiz, houve um decréscimo dos valores até a dose $150 \mathrm{~g} \mathrm{ha}^{-1} \mathrm{e}$ um aumento a partir desta (Figuras 1 a 7). 


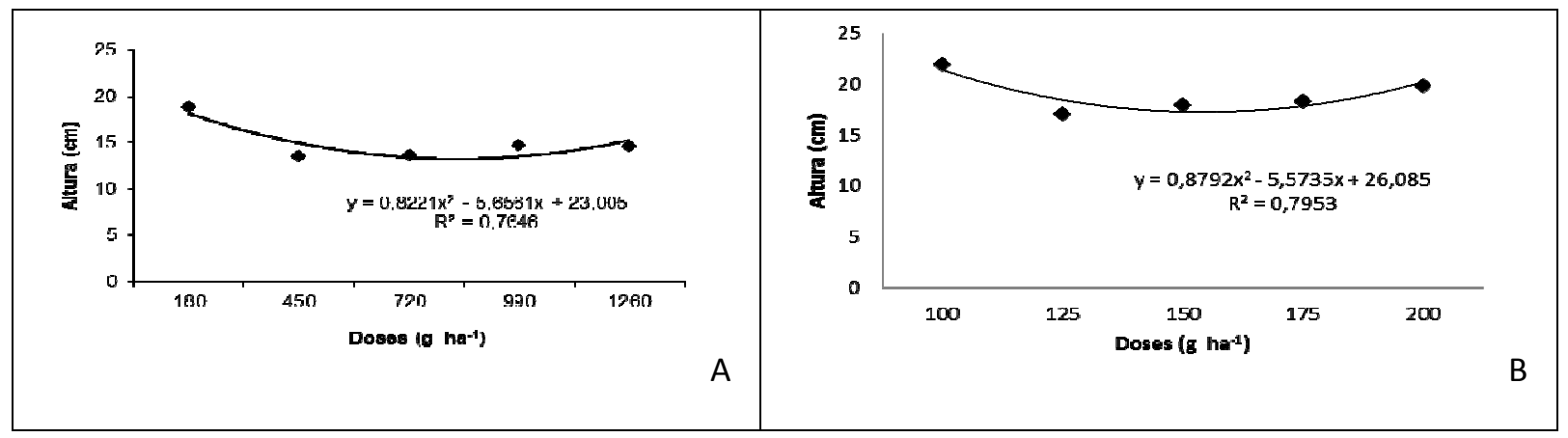

Figura 1 - Altura plantas de pinhão manso, aos 50 dias após a aplicação dos herbicidas glyphosate (A) e fluazifop-p-butil (B) em $\mathrm{g} \mathrm{ha}^{-1}$.

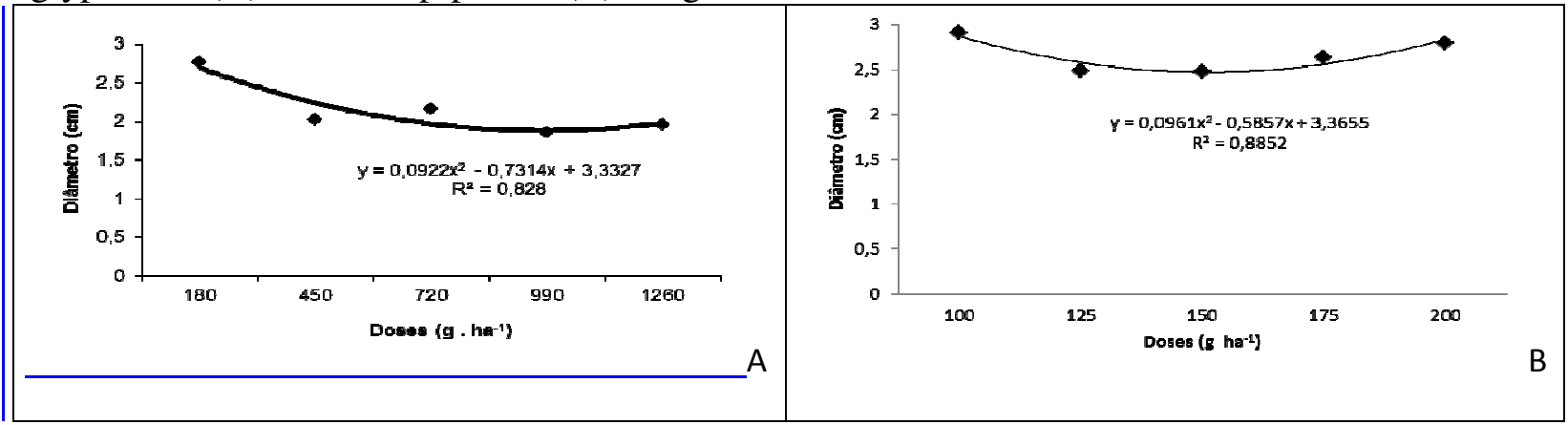

Figura 2 - Diâmetro do caule de plantas de pinhão manso, aos 50 dias após a aplicação dos herbicidas glyphosate (A) e fluazifop-p-butil (B) em $\mathrm{g} \mathrm{ha}^{-1}$.

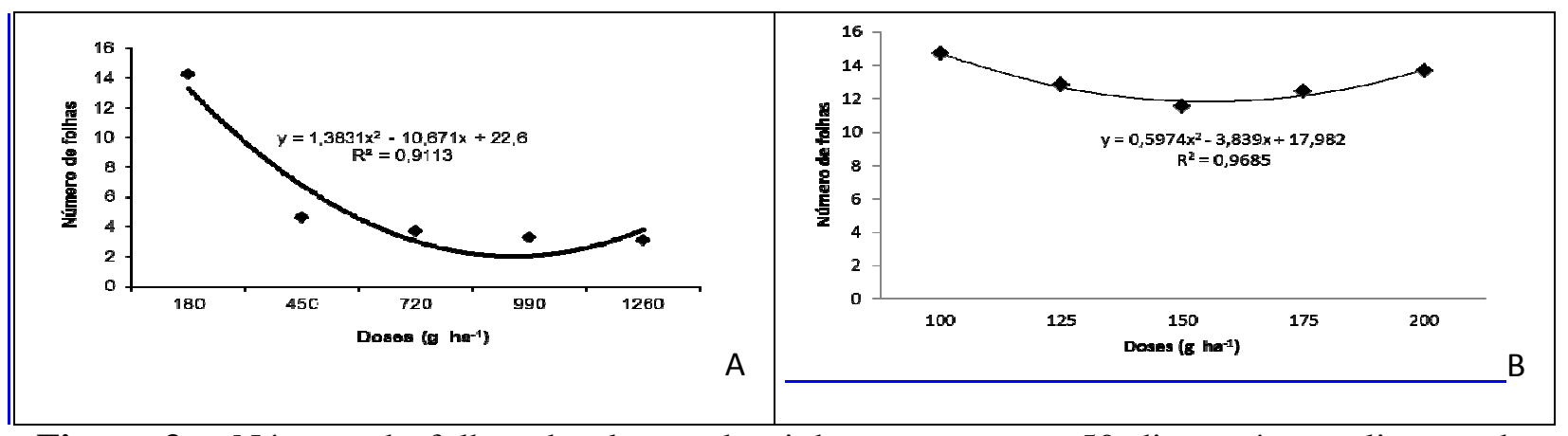

Figura 3 - Número de folhas de plantas de pinhão manso, aos 50 dias após a aplicação dos herbicidas glyphosate (A) e fluazifop-p-butil (B) em $\mathrm{g} \mathrm{ha}^{-1}$. 


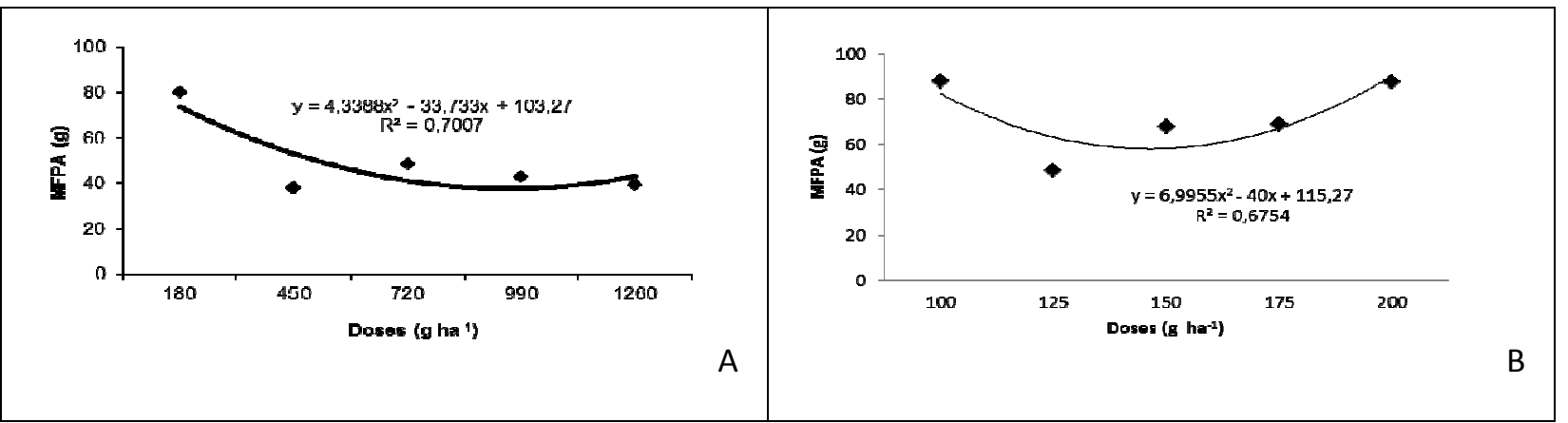

Figura 4 - Matéria fresca da parte aérea (MFPA) de plantas de pinhão manso, aos 50 dias após a aplicação dos herbicidas glyphosate (A) e fluazifop-p-butil (B) $\mathrm{em}^{\mathrm{g} \mathrm{h}} \mathrm{h}^{-1}$.

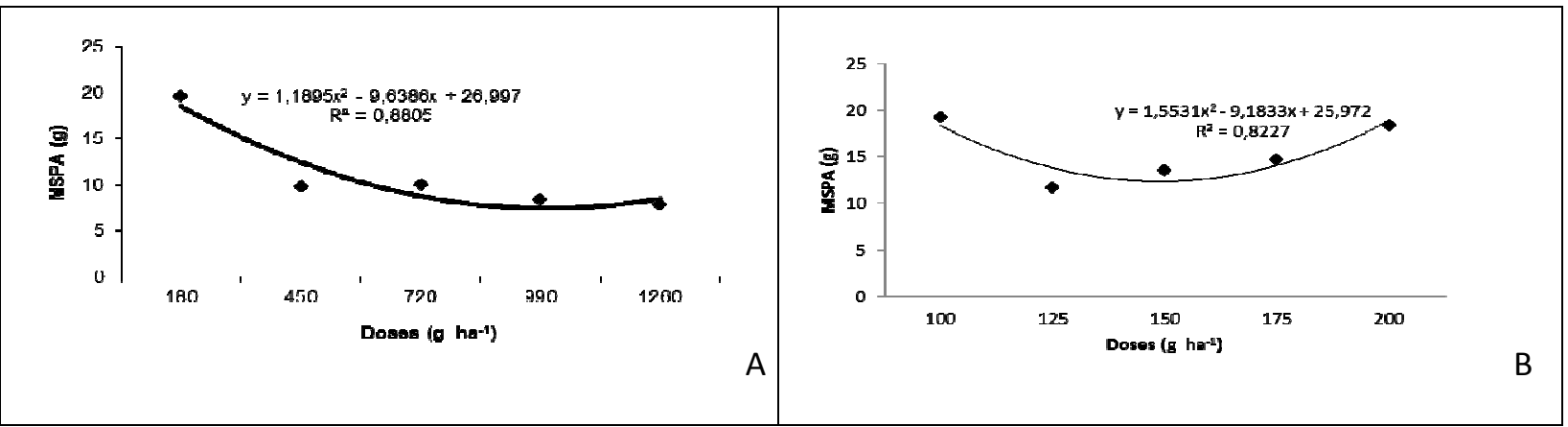

Figura 5 - Matéria seca da parte aérea (MSPA) de plantas de pinhão manso, aos 50 dias após a aplicação dos herbicidas glyphosate (A) e fluazifop-p-butil (B) em $\mathrm{g} \mathrm{ha}^{-1}$.

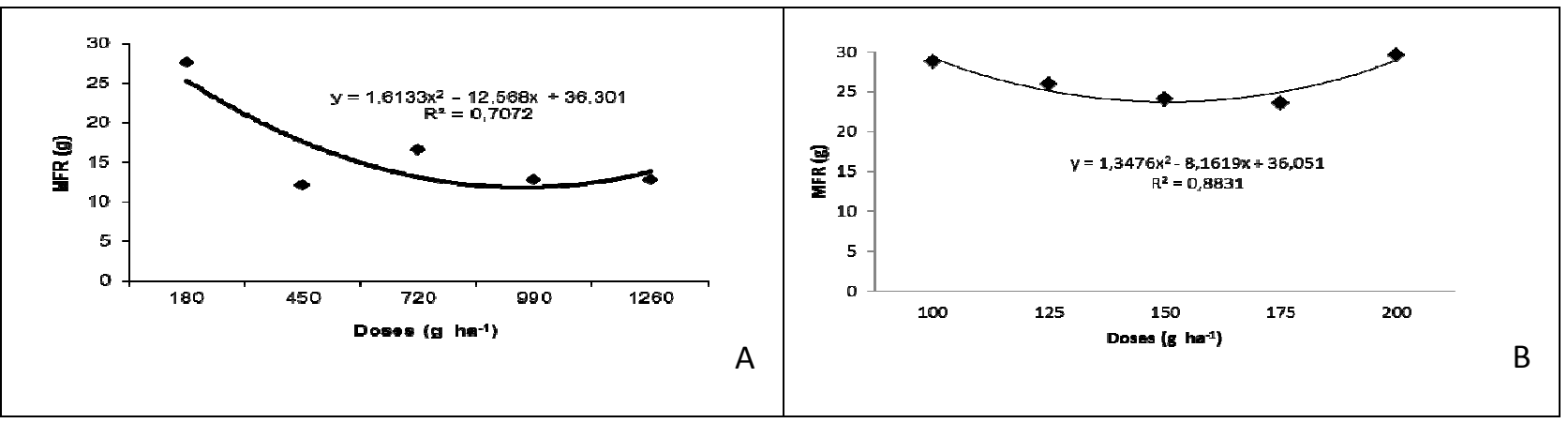

Figura 6 - Matéria fresca da raiz (MFR) de plantas de pinhão manso, aos 50 dias após a aplicação dos herbicidas glyphosate (A) e fluazifop-p-butil (B) em $\mathrm{g} \mathrm{ha}^{-1}$. 


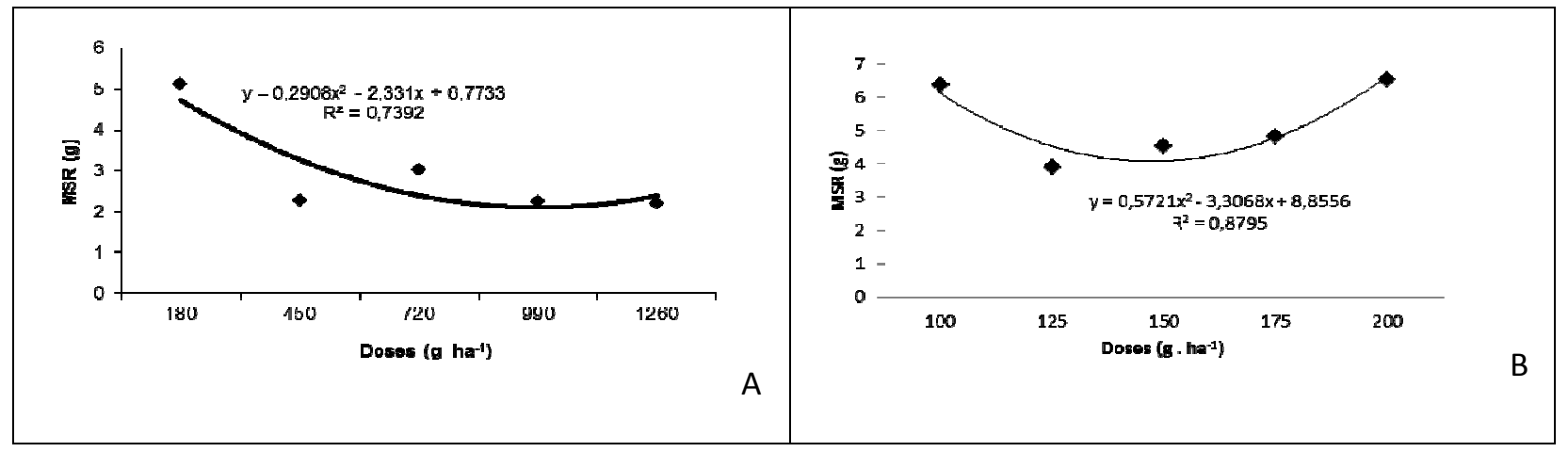

Figura 7 - Matéria seca da raiz (MSR) de plantas de pinhão manso, aos 50 dias após a aplicação dos herbicidas glyphosate (A) e fluazifop-p-butil (B) em $\mathrm{g} \mathrm{ha}^{-1}$.

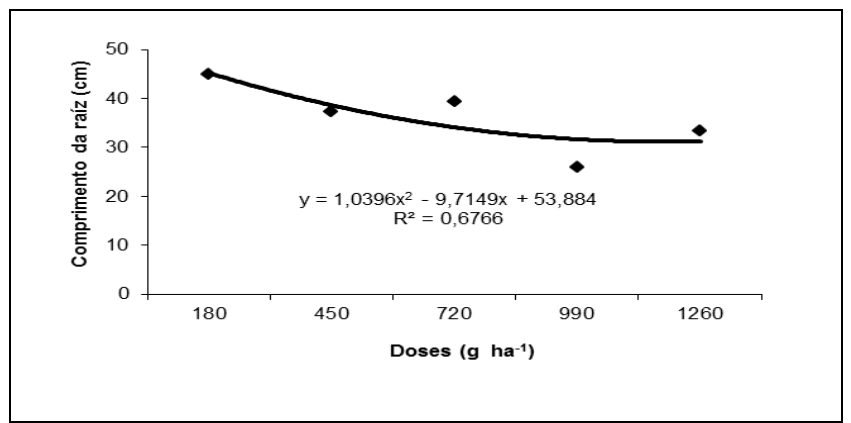

Figura 8 - Comprimento da raiz de plantas de pinhão manso, aos 50 dias após a aplicação dos herbicidas glyphosate em $\mathrm{g} \mathrm{ha}^{-1}$.

Houve diferenças significativas nas interações entre as doses dos herbicidas glyphosate e 2,4-D e as épocas de avaliação, evidenciando o efeito tóxico dos herbicidas aplicados sobre as plantas de pinhão manso, mesmo quando em baixas doses. As plantas tratadas com fluazifop-p-butil não apresentaram sintoma de fitotoxicidade nas doses estudadas, demonstrando a tolerância das plantas de pinhão manso as doses testadas do herbicida. Ronchi \& Silva (2003) também não observaram fitotoxidade em mudas de café devido a aplicação de fluazifop-p-butil. Igualmente, Freitas et al. (2004) observaram que fluazifop-p-butil foi seletivo nas doses 94 e $187 \mathrm{~g} \mathrm{ha}^{-1}$ utilizadas para a cultura da mandioquinha-salsa.

As plantas tratadas com glyphosate apresentaram sintomas de toxidez mais intensos conforme a dose do herbicida foi elevada, nas três primeiras avaliações, aos 9, 18 e 27 DAA (Figura 9). Este resultado concorda com o observado por Alves et al. (2000) na cultura do milho (Zea mays L.), em que os tratamentos com glyphosate provocaram fitotoxicidade a partir da menor dose $\left(57,6 \mathrm{~g} \mathrm{ha}^{-1}\right)$, com incremento desses efeitos, à medida que a dose foi aumentada. Segundo Amarante Júnior et al. (2002), plantas tratadas com glyphosate apresentam sintomas que incluem amarelecimento dos meristemas que progride para necrose e morte lenta, em dias ou semanas. Contudo, apenas sintomas como manchas e necroses foram observados em folhas jovens e restringiram-se a esta parte da planta. As folhas que surgiram posteriormente já não apresentavam sintomas e aos 36 DAA apenas a dose de $990 \mathrm{~g} \mathrm{ha}^{-1}$ apresentou baixa média de fitotoxicidade 
(6,05\%). A partir da terceira avaliação (27 (Figura 9).

DAA) percebeu-se a recuperação das plantas

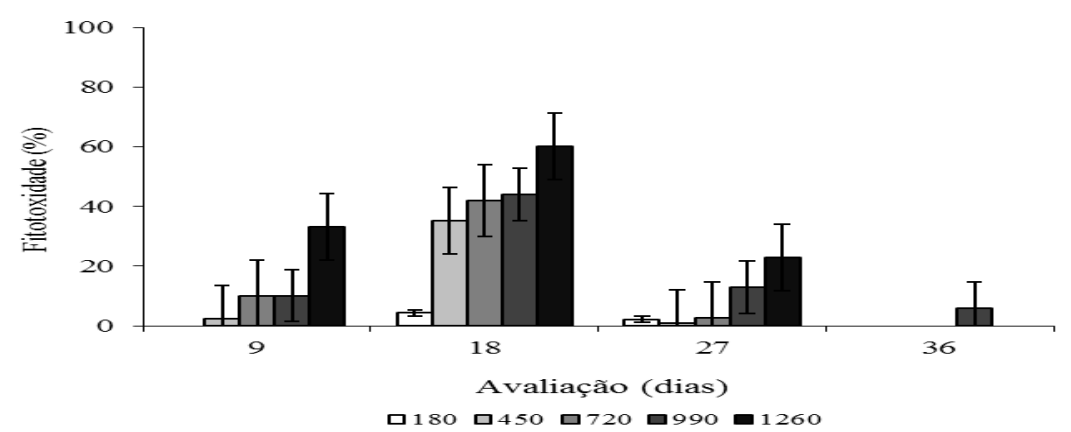

Figura 9 - Fitotoxicidade (\%) e erro padrão da média do glyphosate nas cinco doses $\left(\mathrm{g} \mathrm{ha}^{-1}\right)$ estudadas aos 9, 18, 27 e 36 dias após a aplicação em plantas de pinhão manso.

Nas plantas tratadas com 2,4-D, 30\% das mudas haviam morrido em independente da dose aplicada, os sintomas de decorrência da fitotoxicidade e as mudas fitotoxicidade foram mais intensos, e na restantes estavam totalmente sem folhas ou segunda avaliação, aos 18 DAA, todas as haviam emitido folhas novas que não plantas apresentavam folhas totalmente apresentavam sintomas, o que fez reduzir as encarquilhadas e/ou com manchas amareladas médias de fitotoxicidade (Figura 10). e pecíolos retorcidos. Na terceira avaliação, aos 27 DAA, foi notado aumento de volume e rachaduras no caule, seguido de murchamento das folhas em algumas plantas. Aos 36 DAA,

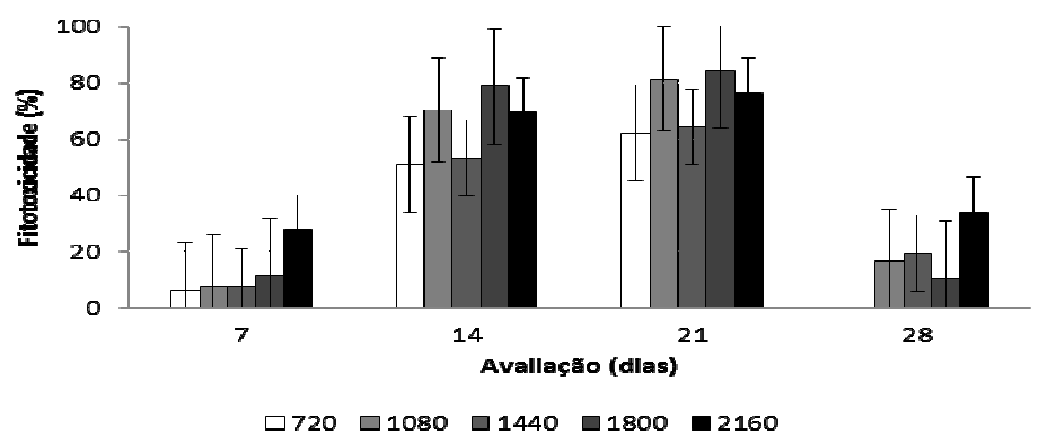

Figura 10 - Fitotoxicidade (\%) e erro padrão da média do 2,4-D amina nas doses ( $\left.\mathrm{L} \mathrm{ha}^{-1}\right)$ estudadas aos 9, 18, 27 e 36 dias após a aplicação em plantas de pinhão manso. 
Estes sintomas causados pela aplicação do 2,4-D são semelhantes aos observados por Albuquerque et al. (2008) quando utilizaram o herbicida em pós-emergência do pinhão manso ou em pré-emergência na dose de $3,5 \mathrm{~L} \mathrm{ha}^{-1} \mathrm{e}$ por Severino et al. (2004) em plantas de mamoneira.

\section{Conclusões}

Conclui-se, portanto, que o fluazifop-pbutil e glyphosate na menor dose (125 e $180 \mathrm{~g}$ $\mathrm{ha}^{-1}$, respectivamente), apresentaram-se seletivos às mudas de pinhão manso. Glyphosate nas quatro maiores doses (450, 720,990 e $1.260 \mathrm{~g} \mathrm{ha}^{-1}$ ) e 2,4-D demonstraram efeitos tóxicos com alterações no aspecto e morfologia das mudas.

\section{Referências}

ALBUQUERQUE, C.J.B. et al. Aplicação de herbicidas em pós-emergência na cultura do pinhão-manso (Jatropha curcas L.). In: CONGRESSO BRASILEIRO DE MAMONA, 3., 2008, Salvador, BA. Disponível em:

$<$ http://www.cnpa.embrapa.br/produtos/mamon a/publicacoes/cbm3/trabalhos/PINHAMANSO /PM 10.pdf>. Acesso em: 24 jan. 2009.

ALCÂNTARA, E.N. Avaliação de herbicidas para cafeeiros em formação. In: SIMPÓSIO DE PESQUISA DOS CAFÉS DO BRASIL, 1., 2000, Poços de Caldas, MG. Resumos Expandidos... Brasília, DF: EMBRAPA CAFÉ, 2000. p.967-970.

ALVES, L.W.R. et al. Efeito da aplicação de subdose dos herbicidas glyphosate e oxyfluorfen, simulando deriva sobre a cultura de milho (Zea mays L.). Ciência Agrotecnologia, v.24, n.4, p.889-897, 2000.

AMARANTE JÚNIOR, O.P. et al. Glyphosate: propriedades, toxicidade, usos e legislação. Química Nova, v.25, n.4, p.589-593, 2002.
ARAÚJO, A.S.F. Biodegradação, extração e análise de glyphosate em dois tipos de solos. 2002. 72 f. Dissertação (Mestrado em Agronomia) - Universidade de São Paulo, Piracicaba, 2002.

FERREIRA, F.A. et al. Mecanismo de ação de herbicidas. In: CONGRESSO BRASILEIRO DE ALGODÃO, 5., 2005, Salvador, BA. Disponível em: http://www.cnpa.embrapa.br/produtos/algodao/ publicacoes/trabalhos_cba5/336.pdf. Acesso em 29/01/2009.

FREITAS, R.S. et al. Seletividade de herbicidas aplicados em pós-emergência para a cultura da mandioquinha-salsa. Planta Daninha, v.22, n.1, p.159-165, 2004.

NUNES, C.F. et al. Efeito da sacarose no cultivo in vitro de embriões zigóticos. In: CONGRESSO DE PLANTAS OLEAGINOSAS, ÓLEOS, GORDURAS E BIODIESEL, 3., 2006, Varginha, MG. Resumos Expandidos... Lavras, MG: UFLA, 2006. v.1. p.1-5.

ROCHA, W.S.D. Sorção de 2,4-D e Diuron nos agregados organominerais de latossolos em função dos conteúdos de massa orgânica e de água. 2003. 75 p. Tese (Doutorado em Agronomia) - Universidade de São Paulo.

RONCHI, C.P.; SILVA, A.A. Tolerância de mudas de café a herbicidas aplicados em pósemergência. Planta Daninha, v.21, n.3, p.421426, 2003.

SATURNINO, H.M. et al. Cultura do pinhãomanso (Jatropha curcas L.). Informe Agropecuário, v.26, n.229, p.44-78, 2005.

SEVERINO, L.S. et al. Sintomas do herbicida 2,4-D em plântulas de mamoneira. In: CONGRESSO BRASILEIRO DE MAMONA, 1., 2004, Campina Grande, PB. Disponível em: $<$ http://www.cnpa.embrapa.br/produtos/mamon a/publicacoes/trabalhos_cbm1/025.PDF>.

Acesso em: 22/01/2009. 
SOCIEDADE BRASILEIRA DA CIÊNCIA DAS PLANTAS DANINHAS - SBCPD. Procedimentos para instalação, avaliação e análise de experimentos com herbicidas. Londrina: 1995. 42p.

TEIXEIRA, L.C. Potencialidades de oleaginosas para produção de biodiesel. Informe Agropecuário, v.26, n.229, p.18-27, 2005.

VARGAS, L.; ROMAN, E.S. Controle de plantas daninhas em pomares. Bento Gonçalves: EMBRAPA, 2003. 26p. (Circular técnica, 47).

VIDAL, R.A. et al. Seletividade do herbicida fluazifop-p-butil para cucurbitáceas. Planta Daninha, v.18, n.3, p.413-417, 2000. 